\title{
Lateral external carotid artery and linguofacial trunk: a rare anatomic variant
}

\begin{abstract}
Knowledge of the variations of the arteries in the carotid triangle is important because its existence can have significant impact on treatment success, especially during surgical or radiological intervention in the region. During routine students dissection of an adult male cadaver as part of a functional human anatomy course, a rare anatomic variant was observed in the carotid triangle on the right side of the neck. The external carotid artery (ECA) and its anterior branches was located lateral to the internal carotid artery (ICA). In addition, the lingual and facial arteries arose in a common linguofacial trunk, which in this configuration coursed medially, crossing and partially obscuring the ICA. Both the hypoglossal and internal laryngeal nerves were at a risk of injury since they lay directly over the linguofacial trunk and the ICA. This is the first case report of a linguofacial trunk arising from a lateral ECA The transposition of the ECA and ICA and presence of a linguofacial trunk could have profound surgical implications including potentially limiting access to the ICA during carotid endarterectomy. It is also expected to cause difficulties for catheter insertion. In addition, the risk of bleeding during pharyngeal surgery is increased in cases in which the ICA is medially displaced due to its anomalous course.
\end{abstract}

Keywords: facial artery, lingual artery, internal carotid artery, hypoglossal nerve, endarterectomy
Volume I Issue I - 2015

\author{
Annette Kirchgessner \\ Dept of Interprofessional Health Sciences and Health \\ Administration, Seton Hall University, USA
}

\begin{abstract}
Correspondence: Annette Kirchgessner, Department of Inter professional Health Sciences and Health Administration, School of Health and Medical Sciences, Seton Hall University, 400 South Orange Avenue, South Orange, NJ 07079, USA, Fax 973275 217I, Email Annette.Kirchgessner@shu.edu
\end{abstract}

Received: April 06, 2015 | Published: May 22, 2015
Abbreviations: ECA, external carotid artery; ICA, internal carotid artery

\section{Introduction}

Knowledge of the possible variations of the external carotid artery (ECA) in the carotid triangle is important, because its existence can have significant impact on treatment success and potentially lead to errors during surgical or radiological intervention in the neck region. The common carotid artery does not give off any branches in the neck, except giving rise to the ECA and internal carotid (ICA) arteries at the carotid bifurcation. The ICA runs a straight course from the carotid bifurcation to the entry in the temporal bone without branching. The ECA supplies anterior branches to head/neck structures including the superior thyroid, lingual and facial arteries. These arteries originate separately from the ECA in $77.8 \%$ of cases $;{ }^{1}$ however, a linguofacial trunk, thryolingual trunk and thyro-linguofacial trunk have also been observed, although much less frequently. ${ }^{2}$ Normally, the ECA lays medial to the ICA. This case report describes a rare anatomic variant in which the ECA lies lateral to the ICA and gives rise to a linguofacial trunk which in this configuration courses anterior to the ICA, greatly hindering its identification.

\section{Case report}

During routine student's dissection as part of a functional human anatomy course, a rare anatomic variant was found at the level of the right carotid triangle of an adult Caucasian male cadaver. On that side, distal to the carotid bifurcation, the ECA and its anterior branches was located lateral to the ICA, medial to the internal jugular vein. After giving off the superior thyroid artery at the carotid bifurcation, a common linguofacial trunk originated from the ECA, which in this configuration coursed medially, crossing and obscuring the ICA, thus potentially limiting surgical access to the vessel (Figure 1A) (Figure 1B). The lingual and facial arteries originated from the linguofacial trunk, medial to the ICA. Slightly distal to the origin of the linguofacial trunk, the ascending pharyngeal artery arose from the ECA traveling between it and the ICA. The hypoglossal nerve coursed lateral to the ECA before passing anterior to the linguofacial trunk and continuing on superior to the digastric tendon. Retraction of the linguofacial trunk, to improve exposure of the ICA, placed the nerve under tension. In addition, the descending branch of the hypoglossal nerve was at a risk of injury since it descended directly over the linguofacial trunk and ICA. As can be seen in Figure 2, the branching pattern of the vessels in the contra lateral carotid triangle was normal without any variations. The left ECA is located medial to the ICA and the superior thyroid, lingual and facial arteries arise separately from the ECA. 


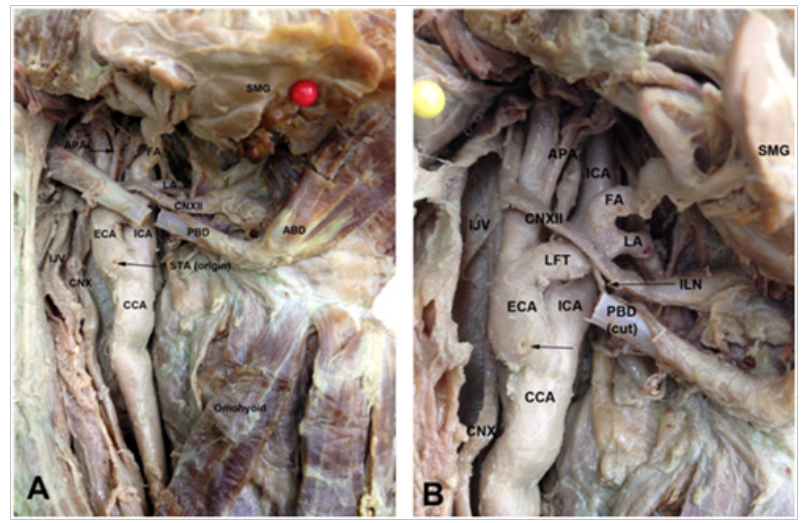

Figure 1 Variant right lateral external carotid artery (ECA) and linguofacial trunk (LFT).

A) The ECA is located lateral to the internal carotid artery (ICA), medial to the internal jugular vein (IJV) and vagus nerve (CNX). The origin of the superior thyroid artery (STA; arrow) from the ECA occurs just distal to the carotid bifurcation.

B) The LFT originates from the lateral ECA and courses medially, crossing and partially obscuring the ICA. The hypoglossal nerve (CNXII) courses lateral to the ECA before coursing medially, crossing the LFT. Its descending branch (DB of CNXII) travels anterior to the LFT and ICA. $\mathrm{ABD}$, anterior belly of the digastric; APA, ascending pharyngeal artery; CCA, common carotid artery; facial artery (FA); lingual artery (LA); PBD, posterior belly of the digastric; SMG, submandibular gland (retracted).

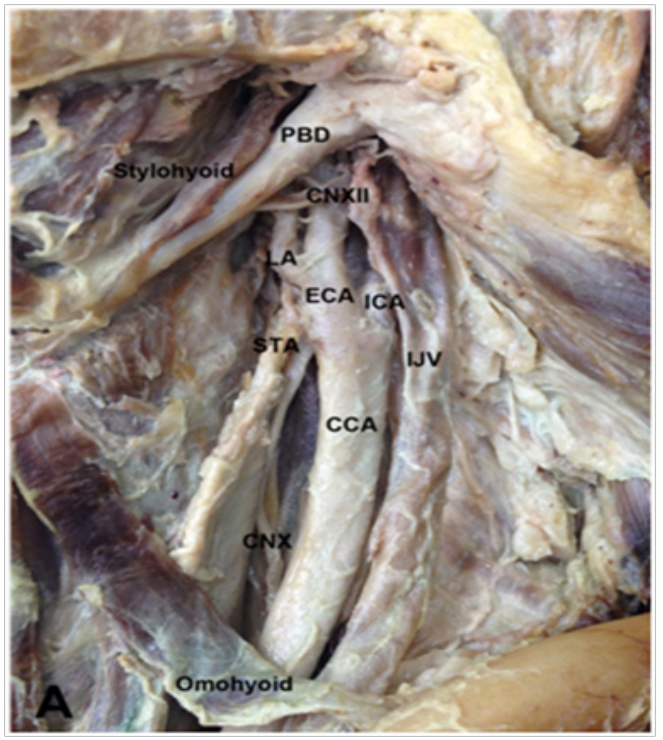

Figure 2 Left carotid triangle. The ECA is located medial to the ICA and gives rise separately to the STA, LA and FA (not visible). The ICA lies just medial to the IJV and ascends posterior to this vessel. The CNXII crosses both the ECA and LA before diving deep to the tendon of the PBD.

\section{Discussion}

This is the first case report to describe the presence of both a lateral ECA and linguofacial trunk in the right carotid triangle. The ECA is normally located medial to the ICA. The incidence of a medial ICA in adults based on a series of angiograms was $4 \% .^{3}$ There was a greater incidence of this finding in patients over 40years of age, and it was more commonly seen on the right than on the left side3.
Cadaveric evidence of a lateral ECA has been infrequently reported. ${ }^{4-6}$ Radiologic evidence of a lateral ECA also exist. ${ }^{7-10}$ In $\sim 78 \%$ of cases, the superior thyroid, lingual and facial arteries originate separately from the ECA. ${ }^{11}$ In their study on human fetuses, Zumre et al. ${ }^{2}$ found a linguofacial trunk in $20 \%$, a thyro-lingual trunk in $2.5 \%$ and a thyrolinguofacial trunk in $2.5 \%$ of the human fetuses studied. ${ }^{2}$ According to Anil et al. ${ }^{12}$ the overall prevalence of a linguofacial trunk in adults is estimated to be $10-20 \% .{ }^{12}$ Yildrim et al. ${ }^{13}$ observed a frequency of $15 \%,{ }^{13}$ while Lappas et al. ${ }^{14}$ and Sanjeev et al. ${ }^{15}$ reported a linguofacial trunk to be present in $14 \%$ and $19 \%$ of cases, respectively. Thus, a lateral ECA and linguofacial trunk are rare anatomic variants and both a lateral ECA and accompanying linguofacial trunk in the right carotid triangle has never before been reported. The ECA is the chief artery of the head and neck region in humans. Thus, the possibility of an inverse disposition of the ICA and ECA must be kept in mind when performing arterial ligatures in the carotid triangle, to avoid damage to the ICA or hemorrhagic accidents. Surgeons and radiologists need to be aware of encountering such arterial variations, as they may lead to iatrogenic injury and misinterpretation of images of the neck region. Variations can pose a danger during surgeries like thyroidectomy, laryngectomy and other neck surgeries, in addition to preoperative selective arterial angiograms, in the management of head and neck tumors. In addition, the branches of the ECA are the key landmarks for adequate exposure and appropriate placement of cross-clamps on the carotid arteries during carotid endarterectomy. It is necessary to understand the surgical anatomy of the carotid arteries to carry out endarterectomy and minimize postoperative complications.

\section{Conclusion}

This case report describes the presence of both a lateral ECA and linguofacial trunk on the right side of the neck. It is important because such malformations are quite rare and can pose a danger during neck surgeries, in addition to serious misinterpretations in clinical diagnosis.

\section{Acknowledgements}

None.

\section{Conflict of interest}

Author declares that there is no conflict of interest.

\section{References}

1. Mata JR, Mata FR, Souza MC, et al. Arrangement and prevalence of branches in the external carotid artery in humans. Ital $J$ Anat Embryol. 2012;117(2):65-74.

2. Zumre O, Salbacak A, Cicekcibasi AE, et al. Investigation of the bifurcation level of the common carotid artery and variations of the branches of the external carotid artery in human fetuses. Ann Anat. 2005;187(4):361-369.

3. Teal JS. Rumbaugh CL, Bergeron RT, et al. Lateral position of the external carotid artery: a rare anomaly? Radiology. 1973;108(1):77-81.

4. Chitra R. Trifurcation of the right common carotid artery. Indian J Plast Surg. 2008;41(1):85-88.

5. Rao SB, Vollala VR, Rao M, et al. Unusual position of external carotid artery: a case report. Indian J Plast Surg. 2005;38(2):170-171.

6. Rusu MC, Vasilescu V, Nimigean V. A rare anatomic variant: the lateral position of the external carotid artery. Oral Maxillofacial Surg. 2006;35(11):1066-1067. 
7. Handa J, Matsuda M, Handa H. Lateral position of the external carotic artery. Report of a case. Radiology. 1972;102(2):361-362.

8. Braeuer NR, Mallamo JT, Lynch RD. Anomalous lateral and inferior position of the external carotid artery: case report. J Can Assoc Radiol. 1975;26(3):210-211.

9. Prendes JL, McKinney WM, Buonanno FS, et al. Anatomic variations of the carotid bifurcation affecting Doppler scan interpretation. J Clin Ultrasound. 1980;8(2):147-150.

10. Bussaka H, Sato N, Oguni T, et al. Lateral position of the external carotid artery. RinshoHoshasen. 1990;35(9):1061-1063.

11. Gluncic V, Petanjek Z, Marusic A, et al. High bifurcation of common carotid artery, anomalous origin of ascending pharyngeal artery and anomalous branching pattern of external carotid artery. Surg Radiol Anat. 2001;23(2):123-125.
12. Anil A, Turgut HB, Peker T, et al. Variations of the branches of the external carotid artery. Gazi Med J. 2000;11:81-83.

13. Yildrin M, Tanyeli E, Solyluoglu AI, et al. Truncus linguofacialis siklig. Morfoloji Der. 2001;9:33-34.

14. Lappas DA, Kamberos SP, Gisakis JG, et al. Anatomic study of the variations in the origin of the branches of the external carotid artery. Beta Medical Arts. 2002:81.

15. Sanjeev IK, Anita H, Aswini M, et al. Branching pattern of external carotid artery in humans. J Clin Diagn Res. 2010;4:3128-3133. 